This item was submitted to Loughborough's Research Repository by the author.

Items in Figshare are protected by copyright, with all rights reserved, unless otherwise indicated.

\title{
Effect of direct-to-consumer genetic tests on health behaviour and anxiety: a survey of consumers and potential consumers
}

PLEASE CITE THE PUBLISHED VERSION

http://dx.doi.org/10.1007/s10897-013-9582-6

\section{PUBLISHER}

Springer ( National Society of Genetic Counselors, Inc.

VERSION

AM (Accepted Manuscript)

LICENCE

CC BY-NC-ND 4.0

\section{REPOSITORY RECORD}

Egglestone, Corin, Anne Morris, and Ann O'Brien. 2019. "Effect of Direct-to-consumer Genetic Tests on Health Behaviour and Anxiety: A Survey of Consumers and Potential Consumers". figshare. https://hdl.handle.net/2134/13183. 
This item was submitted to Loughborough's Institutional Repository (https://dspace.lboro.ac.uk/) by the author and is made available under the following Creative Commons Licence conditions.

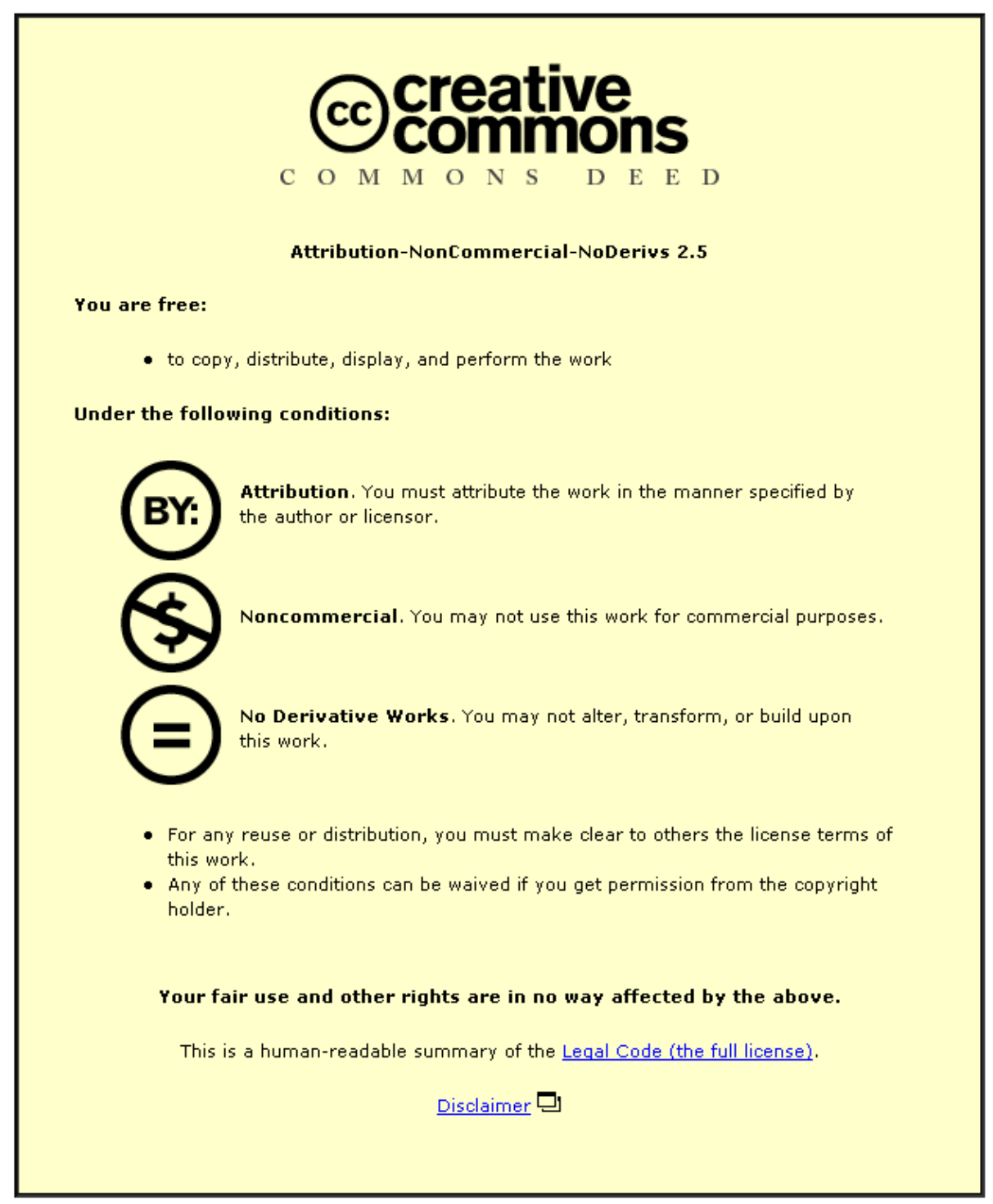

For the full text of this licence, please go to: http://creativecommons.org/licenses/by-nc-nd/2.5/ 
Effect of Direct-to-Consumer Genetic Tests on Health Behaviour and Anxiety: a Survey of Consumers and Potential Consumers

Authors:

Corin Egglestone (doctoral student) - Department of Information Science, Loughborough University, Loughborough, Leicestershire, LE11 3TU, United Kingdom. Email: c.t.r.egglestone3@lboro.ac.uk Telephone: (+44) 01509234861

Professor Anne Morris - Department of Information Science, Loughborough University, Loughborough, Leicestershire, LE11 3TU, United Kingdom. A.Morris@lboro.ac.uk

Dr Ann O'Brien - Department of Information Science, Loughborough University, Loughborough, Leicestershire, LE11 3TU, United Kingdom. A.Obrien@lboro.ac.uk 


\section{Abstract}

Direct-to-consumer (DTC) genetic tests can be purchased over the internet. Some companies claim to provide relative genetic risks for various diseases and thus encourage healthy behaviour. There are concerns that exposure to such information may actually discourage healthy behaviour or increase health anxiety. An online survey was conducted $(n=275)$. Respondents were composed of individuals who had purchased a DTC genetic test and received their results (consumers, $n=189$ ), as well as individuals who were either awaiting test results or considering purchasing a test (potential consumers, $n=86$ ). Consumers were asked if their health behaviour or health anxiety had changed after receiving their results. Respondents' current health behaviour and health anxiety were queried and compared. In total, $27.3 \%$ of consumers claimed a change in health behaviour, all either positive or neutral, with no reported cessation of any existing health behaviour. A change in health anxiety was claimed by $24.6 \%$ of consumers, $85.3 \%$ of which were a reduction. Consumers had significantly better health behaviour scores than potential consumers $(p=0.02)$, with no significant difference in health anxiety.This study points towards an association between receipt of DTC genetic test results and increased adoption of healthy behaviours for a minority of consumers based on self-report, with more mixed results in relation to health anxiety.

\section{Background}

There are many companies that sell direct-to-consumer (DTC) genetic tests which provide consumers with a personalized genetic risk assessment for a variety of complex diseases (as opposed to tests which only focus on monogenic conditions, nutrigenomics, pharmacogenomics or ancestry testing) based on the screening of a large number of potential single nucleotide polymorphisms associated with these diseases (Bloss et al. 2011a; Bloss et al. 2011b; Samuel et al. 2010). Tests are sold directly to consumers, normally with no need for the involvement of health care professionals 
(Bloss et al. 2011a). Although genetic counselling is occasionally provided [such as with Navigenics (Navigenics 2012)], it is by no means a requirement. Many providers of DTC genetic tests claim that they will enable and encourage consumers to improve their health behaviour in relation to diseases for which they are at an increased risk (cf. 23andMe 2012; deCODEme 2012), although there is a large variation in the information provided and claims made on the websites of the different companies (Lachance et al. 2010; Singleton et al. 2012). There are many concerns about DTC genetic tests in the literature. Three common concerns are the limited clinical validity of the disease associations reported by many of the companies (Murray et al. 2010), the differences in genetic risk assessments provided by the various companies (Spencer et al. 2011) and the uncertain clinical significance of the mainly small changes to disease risk associated with the reported SNPs (Samuel et al. 2010).

One main concern is with the effect the genetic risk information provided by the tests may have on the health behaviour and anxiety of consumers. For example, a perceived high risk of disease may increase anxiety and a low risk may discourage healthy behaviour (Samuel et al. 2010). A review of the relevant literature by McBride et al. (2010) concluded there was no evidence that anyone has been harmed by DTC genetic tests. However, there is little research into the effects of DTC genetic tests on the health behaviour and anxiety of consumers and more is "desperately needed" (Bloss et al. 2011a).

To the authors' knowledge, the current study is one of only two studies to date that have examined consumers' perceptions of behaviour change with a sample of "real" consumers of DTC genetic tests (i.e. individuals who have sought out and paid for a test, rather than those who have been offered a free or subsidized test) (for the other see Kaufman et al. 2012), and the only one to compare them with similar individuals who have either not yet purchased a test or not yet received any results. These are important contributions for two reasons. Firstly, results from studies of participants who have been given a free or subsidised DTC genetic test, after they have been asked to participate in a 
study, may not be generalizable to ordinary consumers of a relatively expensive new product.

Secondly, a comparison of consumers of DTC genetic tests with individuals who have either not yet purchased a test or not yet received any results allows for a comparison between two similar groups who differ in the receipt of genetic test results.

A review of the literature found three studies that have examined the effect of DTC genetic tests on groups of consumers. In one of these studies (Kaufman et al. 2012), three of the main DTC genetic testing companies (Navigenics, deCODEme and 23andMe) were asked to dispatch a survey to a random sample of their customers. After receiving their results $(n=1048)$, one third claimed to be taking more care with their diet, $14 \%$ claimed an increase in their level of exercise and $16 \%$ claimed to have made changes to medication or supplements. In another study (Gordon et al. 2011), 60 participants who had been provided with a free test that analyzed genetic risk for eight diseases were interviewed after receiving their results. Approximately one third claimed to have made behavioural changes, such as exercising more, increased diligence in use of sunscreen or checking high risk areas of their results with a healthcare professional. In the third study (Bloss et al 2010; Bloss et al. 2011b), 2037 participants were invited to purchase a test at a heavily subsidized rate and given free access to genetic counselling. After three months, no significant changes were found in participants' level of anxiety, exercise behaviour or the amount of fat consumed in their diet.

Despite the lack of research on the impact of DTC genetic tests for common complex diseases on consumer health behaviour, health anxiety and health outcomes, there is established research into the psychological and behavioural effects of genetic testing for single genes or disorders. For example, a review of the literature on responses to BRCA testing for breast cancer risk found that there was no evidence of psychological harm after testing, and testing could be helpful in reducing worry about breast cancer (Hilgart et al. 2012). A systematic review and meta-analysis of studies investigating the effect of genetic testing for smoking-related disease susceptibility found positive effects on participants' cessation of smoking and motivation to do so in the short term, but not in 
the long term (Smerecnik et al. 2012). The researchers also found no negative effects (e.g. less motivation to stop smoking) if participants were not found to have a high genetic risk. A review by Roberts et al. (2011) examined the effects of genetic testing for susceptibility to Alzheimer's disease. They found no adverse psychological effects of testing. Identified changes to health behaviour included an increase in the use of nutritional supplements and vitamins, and an increase in the purchase of long-term care insurance. However, it is unclear how applicable these results are with regards to the impact of DTC genetic testing for common complex diseases on consumer health behaviour, health anxiety and health outcomes.

Purpose of the Present Study

The purpose of the present study was to examine consumers' perceptions of the effect of genetic risk information, provided by DTC genetic tests, on their health behaviour and health anxiety. The main research questions were:

1. Do consumers believe that their health behaviour or health anxiety have changed due to receipt of genetic tests results, and if so, how have they changed?

2. What are consumers and potential consumers perceptions of their current health behaviour and health anxiety, and is there a significant difference between the two groups?

3. Is there a correlation between consumers' perceived disease risk and their perceptions of their current health behaviour or health anxiety?

\section{Methods}




\section{Participants and Procedures}

As part of a larger study investigating the informational aspects of DTC genetic tests, an online survey was conducted to investigate several issues relating to DTC genetic tests, one of which was consumers' perceptions of health behaviour and anxiety change after receipt of results. Other issues investigated in the survey (but not reported in this paper) included: the information need of consumers (i.e. the information that consumers wished to know about DTC genetic tests, such as their accuracy or coverage), consumers' information seeking behaviour (i.e. the techniques used by consumers to search for information about DTC genetic tests), sources of information consumers used to research DTC genetic tests and consumers' opinions of the quality of information provided on the websites of DTC genetic testing companies (Egglestone et al. 2012). Respondents were contacted via social media, which allowed both those who had purchased a test and received their results (consumers), and those who were considering purchasing a test and those who had purchased a test and not yet received their results (potential consumers) to be contacted. The survey was conducted entirely in English, and a convenience sampling method was used. The majority of respondents were found through the lists of "followers" on the Twitter pages of nine providers of DTC genetic tests. Since private messages cannot be sent to Twitter users who do not "follow" you, only users with a link to a blog, about.me page or similar website in their Twitter user profile were contacted. If an email address was provided on the linked webpage an email invitation was sent; if not a comment was left. Other participants were contacted through messages posted on four relevant internet forums and eight relevant Facebook pages. Several authors of relevant genetics blogs also posted invitations to their readers to participate. Potential consumers were included in the study with the intention of allowing a comparison between two similar groups whose only major difference was the receipt of genetic test results. In line with this intention, any consumers who had not yet received their results, while strictly not potential consumers in the literal sense, were combined with respondents who were considering purchasing a test to create the potential consumers group. Respondents were asked to complete the survey if they had purchased, 
or were considering purchasing, a test that included an estimate of genetic risk for various different diseases. The choice of wording did result in 50 respondents who stated that their main interest was the genealogical, rather than the health, aspects of the tests. However, these respondents were still exposed to the disease risk information, and their inclusion reflects consumers' actual make-up rather than an artificially constrained sample.

Two techniques were used to investigate consumers' perceptions of changes to their health behaviour and health anxiety. The first involved simply asking consumers if their health behaviour or health anxiety had changed in any way due to receiving their results, and if so, how (using openended rather than close-ended questions). These questions provided data on consumers' perceptions about their health behaviour and health anxiety. The second technique sought directly to compare the current health behaviour and health anxiety of the consumers and potential consumers groups, to identify any significant differences between the two groups.

Ethical approval for the study was obtained from the Loughborough University Ethical Advisory Committee.

Instrumentation

There were a total of 44 items in the survey for respondents who had purchased a test, and 39 items for respondents who had not yet done so. The survey was a mixture of open-ended and closeended questions.

In order to assess whether consumers thought their health behaviour had changed due to receipt of DTC genetic test results, the following two questions were asked:

Did your health-related behaviour change at all, either positively or negatively, due to receiving your test results?

If yes, how did it change and have these changes lasted until now? 
Close-ended questions were used to assess respondents' health behaviour in relation to six common health recommendations (inspiration was provided by NHS choices 2012; UCL 2012): a diet with moderate consumption of fat and salt and sufficient consumption of fibre, consumption of five portions of fruit and vegetables per day, smoking abstinence and sufficient levels of exercise. For each health behaviour, respondents were assigned a one or a zero, depending on whether they normally followed or did not follow it respectively; these were added up to create an individual health behaviour score of between zero and six.

Table 1 shows the questions and answer options used to assess health behaviour. The answer options that showed the participant normally followed the health behaviour are marked with a star, with the exception of the questions relating to exercise. For the questions relating to exercise, the requirement was a minimum of 150 minutes of moderate exercise per week, 75 minutes of vigorous exercise per week or an equivalent combination of the two (NHS Choices 2011). 
Table 1: Questions used to assess health behaviour

\begin{tabular}{|c|c|}
\hline Question & Answer Options \\
\hline $\begin{array}{l}\text { What would you estimate the level of salt is in } \\
\text { your diet? }\end{array}$ & $\begin{array}{l}\text { Lower than or equal to recommended levels*, } \\
\text { higher than recommended levels or much higher } \\
\text { than recommended levels. }\end{array}$ \\
\hline $\begin{array}{l}\text { What would you estimate the level of fat is in } \\
\text { your diet? }\end{array}$ & $\begin{array}{l}\text { Lower than or equal to recommended levels*, } \\
\text { higher than recommended levels or much higher } \\
\text { than recommended levels. }\end{array}$ \\
\hline $\begin{array}{l}\text { What would you estimate the level of fibre is in } \\
\text { your diet? }\end{array}$ & $\begin{array}{l}\text { Higher than or equal to recommended levels*, } \\
\text { lower than recommended levels or much lower } \\
\text { than recommended levels. }\end{array}$ \\
\hline $\begin{array}{l}\text { Do you eat at least five items of fruit or } \\
\text { vegetables a day? }\end{array}$ & Never, rarely, some days, most days*, everyday* \\
\hline Do you smoke cigarettes? & $\begin{array}{l}\text { Never*, less than } 1 \text { per day*, between } 1 \text { and } 10 \\
\text { per day, between } 11 \text { and } 20 \text { per day, } \\
\text { over } 20 \text { per day }\end{array}$ \\
\hline Do you smoke cigars or a pipe? & Never*, very occasionally*, occasionally, often \\
\hline $\begin{array}{l}\text { Approximately how much vigorous physical } \\
\text { activity do you do per week? Examples of } \\
\text { vigorous physical activity include running, } \\
\text { jogging, racewalking, cycling at } 10 \text { mph or more, } \\
\text { swimming laps, playing singles tennis, playing } \\
\text { football (soccer), heavy gardening, walking with } \\
\text { a heavy backpack, lifting weights, aerobic } \\
\text { dancing and exercise classes. }\end{array}$ & $\begin{array}{l}\text { Length of time (minutes) } \\
\text { None, } 1 \text { to } 15,16 \text { to } 30,31 \text { to } 45,46 \text { to } 60 \text {, over } \\
60 \\
\text { Number of days per week } \\
1,2,3,4,5,6,7\end{array}$ \\
\hline
\end{tabular}




\begin{tabular}{l|l}
\hline $\begin{array}{l}\text { Approximately how much moderate physical } \\
\text { activity do you do per week? Examples of }\end{array}$ & Length of time (minutes) \\
moderate physical activity include going for a 1 to 15,16 to 30,31 to 45,46 to 60 , over \\
$\begin{array}{l}\text { brisk (at least } 3 \mathrm{mph} \text { ) or long walk, water } \\
\text { aerobics, cycling slower than } 10 \text { mph, playing }\end{array}$ & $1,2,3,4,5,6,7$ \\
doubles tennis, ballroom dancing, general & \\
gardening and carrying heavy bags back from the & \\
shops. & Length of time (minutes) \\
\hline Approximately how much light physical activity & None, 1 to 15,16 to 30,31 to 45,46 to 60, over \\
do you do per week? Examples of light physical & 60 \\
activity include going for a short walk, light & Number of days per week \\
gardening, DIY, light housework and using the & $1,2,3,4,5,6,7$ \\
stairs.
\end{tabular}

In order to assess whether consumers thought their health anxiety had changed due to receipt of DTC genetic test results, the following two questions were asked:

Did your level of health-related anxiety change at all due to receiving your test results? If yes, how did it change and have these changes lasted until now?

To assess perceptions of current health anxiety, all respondents were asked to rate their health anxiety on two items (using a 10-point rating scale where 1=least anxious, and 10=most anxious): one item assessed their anxiety about their health in general, the other item assessed their anxiety about developing a serious disease. These scores were compared between the consumer and potential consumer groups. The wording of the question was:

On a scale of 1 to 10 (1 least anxious, 10 most anxious), how anxious do you normally feel about: 

a. The state of your health
b. The possibility of developing a serious disease

Several demographic questions were asked, including one on socioeconomic status, determined using the National Statistics Socio-economic Classification devised by the UK's Office for National Statistics (Office for National Statistics 2012). Based on their answers to four questions relating to their occupation (or if unemployed or retired from their previous occupation) a matrix was used to assign respondents to one of six categories: (1) managerial and professional occupations, (2) intermediate occupations, (3) small employers and own account workers, (4) lower supervisory and technical occupations, (5) semi-routine and routine occupations and (6) students.

Consumers were asked to rate their general impression of their overall risk of contracting a serious disease based on their complete results. The answer options were: a significantly lower than average risk of disease, a slightly lower than average risk of disease, an average risk of disease, a slightly higher than average risk of disease, and a significantly higher than average risk of disease.

\section{Data Analysis}

As stated above, for the purpose of the analysis all respondents who had purchased a test but not yet received their results were combined with the respondents who were considering purchasing a test to create a potential consumers group.

Qualitative analysis. Consumers who stated that their health behaviour had changed were asked how it had changed with an open-ended question. The answers to this question were postcoded into categories, which were themselves derived from the answers to the question. The categories are shown in table three in Results (with the exception of categories where $n=1$, which were combined into an "Other" category). 
Consumers who stated that their health anxiety had changed were asked how it had changed with an open-ended question. The answers to this question were post-coded into three categories: an increase in health anxiety, a decrease in health anxiety or both an increase and a decrease in health anxiety.

Quantitative analysis. The distributions of the health behaviour scores of the consumers and potentials consumers groups were compared using a two sample Kolmogrov-Smirnov test. This test was chosen as the consumers group's scores were not normally distributed, and it was deemed inappropriate to use a Mann-Whitney $U$ test due to the large number of ties.

The health behaviour scores were then split into two groups, a high score group and a low score group, to compare the proportion of consumers and potential consumers in each score group. The high score group consisted of respondents with a health behaviour score of four, five or six. The low score group consisted of respondents with a health behaviour score of zero, one, two or three. The proportion of consumers and potential consumers in each score group was compared with a twosided Pearson's Chi-Square test.

The percentage of consumers and potential consumers who were assessed as normally following the separate individual health behaviours were compared with a two-sided Pearson's Chi-Square test.

In order to determine if the significant difference between consumers and potential consumers in health behaviour scores was due to underlying demographic variables, a two-sided Fisher's Exact test was used to identify any significant differences in the proportion of the consumers and potential consumers groups in each demographic included in the survey (only respondents who had answered enough questions to be given a health behaviour score were included). A Fisher's Exact test was used instead of a Pearson's Chi-Square test due to the small cell size for some of the categories. For three of the demographic variables (socioeconomic status, ethnicity and country of residence), a large majority of respondents were in one category, with a corresponding small $n$ in the other 
categories. Therefore the categories for these demographics were collapsed, to compare the managerial and professional occupations category against the other categories combined (for socioeconomic status), to compare Caucasian ethnicity against other ethnicities combined (for ethnicity) and to compare residency in USA against residency in all other countries combined (for country of residence). The health behaviour scores were then weighted to control for the different demographic variables and compared with a two sample Kolmogrov-Smirnov test. As above, the categories for socioeconomic status, ethnicity and country of residence were collapsed, due to the large number of respondents in one category in each of the three demographic variables. A stepwise multiple regression was then performed in an attempt to build a model of all predictor variables with health behaviour as the criterion variable. As above, the categories for socioeconomic status, ethnicity and country of residence were collapsed, due to the large number of respondents in one category in each of the three demographic variables.

The distributions of the health anxiety scores of the consumers and potentials consumers groups were compared using a two sample Kolmogrov-Smirnov test. This test was chosen as the consumers group's scores were not normally distributed, and it was deemed inappropriate to use a MannWhitney $U$ test due to the large number of ties.

In order to determine if consumers' perceived risk was correlated with their health behaviour score or health anxiety scores, the five answer options for the question on perceived risk were assigned an ordinal rank from one (significantly lower than average risk of disease) to five (significantly higher than average risk of disease). Since these were ordinal ranks, a Spearman's Rank correlation was used.

\section{Results}

There were 275 usable responses, 189 completed by respondents who had purchased a test and received their results, 22 by respondents who had purchased a test but had not yet received their 
results and 64 by respondents who were considering purchasing a test. Fifty respondents stated that their only reasons for pursuing DTC genetic tests were genealogical. However, all respondents who had purchased a test had purchased one which included estimated genetic risks for more than one disease.

In order to increase the response rate, all questions were voluntary. Therefore, all results refer only to respondents who supplied enough data to be included in the particular analysis the result refers to, with percentages referring to the percentage of respondents included in the analysis rather than the total number of respondents. The same is true for descriptive statistics.

As stated above (see methods), for the purpose of the analysis all respondents who had purchased a test but not yet received their results were combined with respondents who were considering purchasing a test to create a potential consumers group. The health behaviour scores of these two groups were compared using an independent samples t-test in order to assess their compatibility. This test was chosen as the scores for both groups were normally distributed. The mean health behaviour scores for those who had not purchased a test was 3.67 and the mean of those who had not yet received their results was 3.58 , a difference of 0.09 . The mode for both groups was 3 , with almost identical standard deviation $(1.37,1.35)$. An independent samples t-test found no significant difference between the two $(p=0.81)$.

\section{Respondent Demographics}

In total, $62.7 \%$ of the respondents were male and $37.3 \%$ female. The vast majority $(84.6 \%)$ of respondents described themselves as Caucasian or White. This was followed by mixed race with $6.7 \%$ of respondents. Respondents resided in a wide variety of countries, 22 in total. A large majority (70.5\%) resided in the USA, followed by the UK (9.6\%), Canada (6.5\%) and Australia (3.1\%). The mode age group was $30-44$ with $33.5 \%$ of respondents, the mode education level was a 
postgraduate degree with $53.6 \%$ of respondents and the mode socioeconomic category was managerial and professional occupations (see methods) with $83.5 \%$ of respondents.

Table 2 shows the demographics of the consumers and potential consumers groups. Both groups had the same mode group for gender, education level, socioeconomic category, country of residence and ethnicity. 
Table 2: Respondent Demographics $(N=275)$

\begin{tabular}{|c|c|c|c|}
\hline \multicolumn{2}{|l|}{ Demographic } & \multirow{2}{*}{$\begin{array}{l}\text { Consumers } \\
n=189 \\
\text { Percentage }(n)\end{array}$} & \multirow{2}{*}{$\begin{array}{l}\text { Potential } \\
\text { Consumers } \\
n=86 \\
\text { Percentage }(n)\end{array}$} \\
\hline & & & \\
\hline Gender & Male & $63.0(114)$ & $62.2(51)$ \\
\hline & Female & $37.0(67)$ & $37.8(31)$ \\
\hline Age group & $18-29$ & $22.0(40)$ & $45.7(37)$ \\
\hline & $30-44$ & $31.9(58)$ & $37.0(30)$ \\
\hline & $45-60$ & $27.5(50)$ & $13.6(11)$ \\
\hline & $60+$ & $18.7(34)$ & $3.7(3)$ \\
\hline Education level $^{1}$ & High school & $3.4(6)$ & $3.7(3)$ \\
\hline & Post-high school & $2.2(4)$ & $4.9(4)$ \\
\hline & Bachelors degree & $39.1(70)$ & $42.0(34)$ \\
\hline & Postgraduate degree & $55.3(99)$ & $49.4(40)$ \\
\hline $\begin{array}{l}\text { Socioeconomic } \\
\text { category }\end{array}$ & $\begin{array}{l}\text { Managerial and } \\
\text { professional occupations }\end{array}$ & $86.4(152)$ & $77.2(61)$ \\
\hline & Intermediate occupations & $4.0(7)$ & $5.1(4)$ \\
\hline & Small employers and own & $2.8(5)$ & $6.3(5)$ \\
\hline
\end{tabular}

\footnotetext{
${ }^{1}$ Education level refers to respondents who have started but not necessarily completed that level of education
} 


\begin{tabular}{|c|c|c|c|}
\hline \multicolumn{4}{|c|}{ account workers } \\
\hline & $\begin{array}{l}\text { Lower supervisory and } \\
\text { technical occupations }\end{array}$ & $1.7(3)$ & $1.3(1)$ \\
\hline & $\begin{array}{l}\text { Semi-routine and routine } \\
\text { occupations }\end{array}$ & $1.1(2)$ & $1.3(1)$ \\
\hline & Students & $4.0(7)$ & $8.9(7)$ \\
\hline Country of & USA & $71.8(130)$ & $67.5(54)$ \\
\hline restaence & UK & $9.4(17)$ & $10.0(8)$ \\
\hline & Canada & $6.6(12)$ & $6.3(5)$ \\
\hline & Australia & $3.9(7)$ & $1.3(1)$ \\
\hline & Other & $8.3(15)$ & $15.0(12)$ \\
\hline Ethnicity & Caucasian & 84.2 (149) & $85.5(65)$ \\
\hline & Mixed-race & $7.3(13)$ & $5.3(4)$ \\
\hline & Asian & $2.8(5)$ & $9.2(7)$ \\
\hline & Other & $5.6(10)$ & $0(0)$ \\
\hline
\end{tabular}

Health Behaviour

When asked whether their health behaviour had changed due to receiving their test results, $27.3 \%$ $(n=50)$ of consumers stated that it had and $72.7 \%(n=133)$ stated that it had not. Out of the fifty consumers who stated that their behaviour had changed, 45 (90\%) described how it had the 
changed. Table 3 shows these changes in health behaviour and the percentage of respondents who mentioned each (some respondents mentioned more than one change to health behaviour). The most common change was "healthier diet" (53.3\%), followed by "more exercise" (26.7\%) and "taking vitamins or supplements" (13.3\%).

Table 3: Consumers' self-reported changes to health behaviour after receiving DTC genetic test results $(n=45)^{\mathrm{a}}$

Change in Health Behaviour

Healthier diet

More exercise

Taking vitamins or supplements

Preventative checks such as eye tests

Looking into high risk items (either research, talking with doctor or medical tests)

Stopped or reduced caffeine intake

Lost weight

Generally more health conscious

Generally reducing risk conditions

Other (e.g. wearing sunglasses)

Table 4 shows the health behaviour scores for the consumers and potential consumers groups.

\footnotetext{
${ }^{a}$ Responses were not mutually exclusive and therefore add up to more than the number of respondents (45)
} 
Table 4: Health behaviour scores of the consumers and potential consumers groups ${ }^{a}$ $(\mathrm{N}=216)$

\begin{tabular}{l|ll} 
Health behaviour score & Consumers & Potential consumers \\
& Percentage $(n)$ & Percentage $(n)$ \\
\hline 0 & $1.3(2)$ & $1.6(1)$ \\
$2.0(3)$ & $4.7(3)$ \\
2 & $11.2(17)$ & $9.4(6)$ \\
3 & $13.2(20)$ & $34.4(22)$ \\
4 & $24.3(37)$ & $20.3(13)$ \\
5 & $30.9(47)$ & $21.9(14)$ \\
6 & $17.1(26)$ & $7.8(5)$ \\
\hline Total & $100(152)$ & $100(64)$ \\
& &
\end{tabular}

The consumers' scores were generally higher than the potential consumers', with a mode of five and three respectively. The mean scores were 4.18 and 3.64 respectively, a difference of 0.54 . A two sample Kolmogrov-Smirnov test found a significant difference between the distribution of health behaviour scores in the two groups $(p=0.02)$.

The scores were then split into two groups: a high score group and a low score group. A two-sided Pearson's Chi-Square test showed that there was a significant difference between the proportion of consumers and potential consumers in each score group $X^{2}(1, n=216)=10.01, p=0.00$, with $72.4 \%$ of consumers and $50.0 \%$ of potential consumers in the high score group, compared with $27.6 \%$ of consumers and $50.0 \%$ of potential consumers in the low score group.

\footnotetext{
${ }^{\text {a }}$ See methods
} 
Table 5 shows the percentage of respondents in the consumers and potential consumers groups who were classified as normally following each health behaviour. For both groups the health behaviour normally followed by the highest percentage of respondents was smoking abstinence, followed by sufficient fibre intake and sufficient exercise.

Table 5: Percentage of respondents in consumers and potential consumers groups who were classified as normally following each health behaviour $(n=263)$

\begin{tabular}{l|ll} 
Health behaviour & Consumers & Potential consumers \\
& Percentage $(n)$ & Percentage $(n)$ \\
Smoking abstinence & $92.7(166)$ & $93.8(76)$ \\
Sufficient fibre intake & $74.0(125)$ & $64.5(49)$ \\
Sufficient exercise & $66.3(114)$ & $61.0(47)$ \\
Moderate salt intake & $63.7(109)$ & $55.1(38)$ \\
Moderate fat intake & $57.1(101)$ & $50.7(37)$ \\
Sufficient fruit and vegetable intake & $53.6(97)$ & $38.8(31)$
\end{tabular}

With the exception of smoking abstinence (where the proportions were almost identical), for each health behaviour a higher percentage of the consumers group normally followed the health recommendations than the potential consumers group, although the only significant difference was for fruit and vegetable intake. A two-sided Pearson's Chi-Square test found a significant difference between the two groups in the percentage who normally had a sufficient fruit and vegetable intake $\mathrm{x}^{2}(1, n=261)=4.89, p=0.03$, but not in the percentage who normally had a moderate salt intake, a moderate fat intake, sufficient fibre intake, sufficient exercise or who were normally abstinent from smoking.

Respondent demographic variables (age, proportion in the managerial and professional occupations socioeconomic category, gender, proportion of Caucasian ethnicity, education level, proportion 
residing in the USA) were analysed to determine whether they accounted for the difference in health behaviour scores. A two-sided Fisher's Exact test found one significant difference between the consumers and potential consumers groups for age $(p=0.00)$, with consumers significantly more likely to be in an older age group than potential consumers. Significant differences were found between the consumers and potential consumers groups when weighted for age $(p=0.03)$, two socioeconomic categories (the managerial and professional occupations category versus the other categories combined) ( $p=0.03)$, ethnicity (Caucasian versus other ethnicities combined) $(p=0.05)$, education level ( $p=0.03$ ) and country of residence (USA versus other countries combined) $(p=$ 0.01). A stepwise multiple regression was then performed in an attempt to build a model of all predictor variables for health behaviour scores. Table 6 shows the results of this analysis. The only significant predictor variable was membership in consumers or potential consumers group $(B=-$ 0.48$, SE B $=-0.16, p=0.03)$.

Table 6: Results of multiple regression analysis

\begin{tabular}{l|lc} 
Variable & Coefficient & \\
\hline Membership of consumers or potential & $\mathrm{B}=-0.48$ & 0.03 \\
consumers group & SE B $=-0.16$ & \\
Gender & Beta In $=-0.14$ & 0.06 \\
Education Level & Beta In $=0.12$ & 0.09 \\
Membership of managerial and professional & Beta In $=-0.08$ & 0.28 \\
occupations socioeconomic category & & \\
Residence in USA & Beta In $=-0.06$ & 0.39 \\
Caucasian Ethnicity & Beta In $=0.05$ & 0.47 \\
Age Group & Beta In $=0.12$ & 0.67 \\
\hline $\mathbf{N}$ & &
\end{tabular}




\section{Health Anxiety}

When asked whether their health anxiety had changed due to receiving their results, $24.6 \%(n=45)$ stated that it had and $75.4 \%(n=138)$ stated that it had not. Of those whose anxiety changed, $75.6 \%$ $(n=34)$ described how it had changed; $85.3 \%(n=29)$ stated that their anxiety had decreased, three individuals reported that it had increased and two stated that it had both increased and decreased. The vast majority of respondents who described how their health anxiety had changed reported that it had only changed by a small amount.

For general anxiety about health, the mean score for the consumers group was 3.80 and for the potential consumers group it was 4.22, a difference of 0.42 . The mode score for both groups was 2 . A two sample Kolmogrov-Smirnov test found no significant difference in the distribution of anxiety scores between the two groups $(p=0.63)$.

For anxiety about developing a serious disease, the mean score for the consumers group was 3.52 and for the potential consumers group it was 3.92, a difference of 0.40 . The mode score for both groups was 2. A two sample Kolmogrov-Smirnov test found no significant difference in the distribution of anxiety scores between the two groups $(p=0.30)$.

\section{Perceived Risk}

Table 7 shows consumers' reported perception of their overall risk of serious disease based on their DTC genetic test results. The results follow a rough bell curve, with over half of consumers reporting an impression of an average risk of disease. 
Table 7: Consumers' reported perceived risk of serious disease based on DTC genetic test results $(n=171)$

\begin{tabular}{l|l} 
Impression of disease risk & Percentage $(n)$ \\
\hline Significantly lower than average risk of disease & $2.9(5)$
\end{tabular}

Slightly lower than average risk of disease

Average risk of disease

Slightly higher than average risk of disease

$14.0(24)$

Significantly higher than average risk of disease

$4.7(8)$

Using Spearman's Rank correlation, no significant correlation was found between perceived risk and health behaviour score $(r=-0.08, n=141, p=0.36$, two-tailed), general anxiety about health $(r=$ $0.10, n=165, p=0.20$, two-tailed) or anxiety about developing a serious disease $(r=0.15, n=165, p$ $=0.06$, two-tailed).

\section{Discussion}

As stated earlier, to the authors' knowledge the current study is one of only two studies whose participants were "real" consumers of DTC genetic tests (for the other see Kaufman et al. 2012). Also, a unique aspect of the present study is the inclusion of a group of respondents who had not received any DTC genetic test results (the potential consumers group), which was composed of respondents who had purchased a test but not yet received their results and respondents who had not purchased a test but were seriously considering doing so. The inclusion of a potential consumers group is an important contribution, as respondents from this group were similar in terms of demographics and health related issues (such as interest in DTC genetic tests) to consumers who have received their results. This allowed an investigation into consumers' perceptions of health behaviour and anxiety change after receiving their results, by comparing the two groups' perceptions of their current health behaviour and anxiety. Although causation can never be 
established from a cross-sectional survey, the use of the two techniques to investigate consumers' perceptions of changes to health behaviour and anxiety after receipt of DTC genetic test results (i.e. both asking if changes had occurred and comparing perceptions of current behaviour and anxiety), the repeat of the significance tests with demographic weighting and the use of stepwise multiple regression to identify predictors of health behaviour adds validity to the results.

With regard to reported changes to health behaviour, the percentage of consumers who reported a change (27.3\%) was similar to that of Gordon et al. (2011), who found that approximately one third of respondents reported changes. It is not clear why almost three quarters of respondents in the current study reported making no changes to their health behaviour. In the study conducted by Gordon et al. (2011), the most common reasons given by participants for making no behavioural changes were that they were already practising healthy behaviours, they had not been found to be at an increased risk for any disease tested or that they were simply not surprised by the results. These explanations may also apply to the current study. Indeed, with regard to participants already practising healthy behaviours, even amongst the potential consumers group half of the respondents self-reported as following four, five or six of the health behaviours, leaving little room for improvement. However, no information on these issues was collected in the survey, so it is only possible to speculate.

The total percentage of respondents who reported a change in health behaviour in the study by Kaufman et al (2012) is not clear, but many of the reported changes to health behaviour were similar to the current study, such as improved diet, increased exercise or changes to vitamins or supplements. When the agreement of the current study with these two previous studies is considered along with the difference found between the health behaviours of the consumers and potential consumers groups in the current study, the evidence points towards an association between receipt of DTC genetic test results and better reported health behaviour for a minority of individuals. The association between receipt of DTC genetic test results and better reported health 
behaviour may have been due to receipt of the test results, but again it must be emphasized that without experimental manipulation no causal effects can be assumed. The results might also be explained by underlying differences between those who have taken a genetic test and those who have not. Even if the association is due to receipt of DTC genetic test results, it is unclear whether this association is due to the genetic risk information itself, or whether other factors such as increased information about diseases and preventative health behaviour could be the cause.

Although the findings of the current study are contrary to those of Bloss et al. (2011b), the difference may be due to the analysis of only two types of health behaviour in their study, compared with six in the current study, or due to differences between "real" consumers and individuals offered a subsidized test. No respondents in the current study reported any negative changes to health behaviour. This corresponds with the findings of research into genetic testing for smoking-related disease susceptibility, where no evidence of negative effects on health behaviour have been found in participants who have tested negative for a gene increasing their risk for a smoking related disease (Smerecnik et al. 2012). This finding is noteworthy given the concerns of some commentators that a reported low genetic predisposition to disease may discourage healthy behaviour (cf. Samuel et al. 2010).

Interestingly, six participants reported that they had started taking vitamins or dietary supplements, a change in health behaviour identified by Roberts et al.(2011) in relation to genetic testing for susceptibility to Alzheimer's disease. With these results in mind, it may be advisable for future studies to analyze a wider range of health behaviours than the current study, including some of the behaviours mentioned in the open-ended question on health behaviour change. As well as supplements, these behaviours could perhaps include: preventative checks, reduced caffeine consumption and reduced weight.

The demographics of the respondents of the current study are broadly similar to those in the studies reported by Kaufman et al. (2012) and Bloss et al. (2011b). Namely, participants have been mainly 
of a white/Caucasian ethnicity, members of a high socioeconomic or income group, possessed a high level of education and are in a middle age range. However, there is some difference in gender, with $62.7 \%$ of participants in the current study self-identifying as male, compared with $54 \%$ in the study by Kaufman et al. (2012) and $44.7 \%$ in the study by Bloss et al. (2011b).

The findings in relation to health anxiety are less clear than those relating to health behaviour. Although many respondents claimed a change in anxiety after receiving their results, no significant differences in anxiety levels were found between the consumers and potential consumers groups. The lack of a significant difference may signify that any effect the tests have on anxiety are too small to be identified with the method used, or that respondents may be inaccurate in their reporting of anxiety levels or changes to anxiety. However, if respondents' reports of changes to anxiety are correct, then a large majority of respondents had no increase in health anxiety. These results are similar to findings from studies investigating the effects of BRCA testing for susceptibility to breast cancer and ApoE testing for susceptibility to Alzheimer's disease (Hilgart et al. 2012; Roberts et al. 2011). However, it is important to note that some respondents, albeit a small minority, reported an increase in health anxiety.

No significant correlation was found between perceived risk and health behaviour score, general anxiety about health or anxiety about developing a serious disease. However, it should be noted that the design of the question is a limitation. Consumers were asked about their perception of their overall disease risk based on their results. Because of the complex nature of DTC genetic test results, which often show an increased risk for some diseases and a decreased risk for others, it can be difficult for consumers to condense their results into an overall impression of their disease risk. Therefore it would be inappropriate to draw any conclusions from these findings. 
Study Limitations

There are several other limitations to the current study that should be noted. The method of contacting potential participants created a selection bias which excluded non-computer literate individuals and those who do not use social media, and may have underrepresented consumers with a prior bad experience with the tests. However, given the small size of the population of consumers of DTC genetic tests, social media was the only feasible way to contact "real" consumers whilst remaining independent from the providers of DTC genetic tests, and allowed for the inclusion of potential consumers in the study. Also, as consumers need to be reasonably computer literate to actually purchase a test (only available through websites), the potential for bias in respect to computer literacy should be at a minimum. A second limitation regards assessing health behaviour. As health behaviour was not directly measured, the answers were subjective, and the lack of a validated screener item is a major limitation. Also, the assessment of only six health behaviours (four diet-related) in the comparison between the consumers and potential consumers groups may have influenced the results, possibly affecting the size of the difference found between the two groups, as any difference in other health behaviours (e.g. supplements, preventative checks) identified in the open-ended question on health behaviours, would not have been included. Another limitation of the study was the lack of a baseline measure, which meant that comparison of behaviour before and after receipt of results was not possible. The lack of a validated or baseline measure was also a limitation of the assessment of health anxiety. Another limitation was caused by the combination of respondents who had not yet purchased a test and respondents who had purchased a test but not yet received their results into one group. Although it was assumed that these groups were similar, there may have been differences between respondents who had purchased a test and those who had only contemplated doing so. A final limitation of the study is that respondents purchased tests from a variety of different DTC genetic testing companies. Their responses may have been influenced by the different disease risks assessed and the different methods of reporting results among companies. A majority of participants purchased a test from 
one particular company, leaving inadequate statistical power to compare differences between those individuals and others who had purchased a test from a different company.

Practice Implications

Genetic counsellors are likely to come into contact with patients who have purchased DTC genetic tests, and have a role in helping them to understand their results (Gordon et al. 2011). Although there is likely an element of risk to patients' exposure to genetic risk information (cf. Samuel et al. 2010), it is important to remember that there is a potential for the test results to have a positive impact, and that improvements in health behaviour and reductions in health anxiety may occur. Genetic counsellors should aim to provide guidance which will foster these outcomes.

Research Recommendations

Future work will involve an in-depth assessment of how the results from DTC genetic tests affect behaviour and anxiety amongst "real" consumers. This will take the form of in-depth interviews of a sample of consumers of DTC genetic tests, and will focus on the mechanism by which the genetic risk information from a DTC genetic test can affect an individual's health behaviour or health anxiety. This will include an examination of the interaction between health behaviour and health anxiety, and will examine factors such as severity of results, surprise caused by results, opinions on quality of results, general attitudes towards health, health behaviour and disease, knowledge of genetics and utilisation of healthcare in relation to results.

\section{References}

23andMe. Disease risk. Available at https://www.23andme.com/health/risks Last visited March 12, 2012.

Bloss, C.S., Darst, D.F., Topol, E.J., \& Schork, N.J. (2011a). Direct-to-consumer personalized genomic testing. Human Molecular Genetics, 20(R2), R132-141. 
Bloss, C.S., Ornowski, L., Silver, E., et al. (2010). Consumer perceptions of direct-to-consumer personalized genomic risk assessments. Genetics in Medicine, 12(9), 556-566.

Bloss, C.S., Schork, N.J., \& Topol, E.J. (2011b). Effect of direct-to-consumer genomewide profiling to assess disease risk. New England Journal of Medicine, 364(6), 524-534.

deCODEme. Health. Available at http://www.decodeme.com/genes-and-health Last visited March 12, 2012.

Egglestone, C., Morris, A. \& O'Brien, A. (2012). The informatics of direct-to-consumer genetic tests (conference abstract). $13^{\text {th }}$ EAHIL Conference: Health Information Without Frontiers. Available at http://sites-final.uclouvain.be/EAHIL2012/conference/?q=node/1394 Last visited November 5, 2012.

Gordon, E.S., Griffin, G., Wawak, L., Pang, H., Gollust, S.E., \& Bernhardt, B.A. (2011). “It's not like judgement day": public understanding of and reactions to personalized genomic risk information. Journal of Genetic Counseling. epub ahead of print.

Hilgart, J.S., Coles, B. \& Iredale, R. (2012). Cancer genetic risk assessment for individuals at risk of familial breast cancer. Cochrane Database of Systematic Reviews, 15(2), CD003721.

Kaufman, D.J., Bollinger, J.M., Dvoskin, R.L., \& Scott, J.A. (2012). Risky business: risk perception and the use of medical services among customers of DTC personal genetic testing. Journal of Genetic Counseling. epub ahead of print.

Lachance, C.R., Erby, L.A.H., Ford, B.M., Allen, V.C.Jr., \& Kaphingst, K.A. (2010). Informational content, literacy demands, and usability of websites offering health-related genetic tests directly to consumers. Genetics IN Medicine, 12(5), 304-312.

McBride, C.M., Wade, C.H., \& Kaphingst, K.A. (2010). Consumers' views of direct-to-consumer genetic information. Annual Review of Genomics and Human Genetics, 22(11), 427-446. 
Murray, A.B., Carson, M.J., Morris, C.A., \& Beckwith, J. (2010). Illusions of scientific legitimacy: misrepresented science in the direct-to-consumer genetic-testing marketplace. Trends in Genetics, 26(11), 459-461.

Navigenics. Genetic counselling. Available at http://www.navigenics.com/visitor/what we offer/genetic counseling Last visited March 12, 2012. NHS choices (2011). Physical activity guidelines for adults. Available at http://www.nhs.uk/Livewell/fitness/Pages/physical-activity-guidelines-for-adults.aspx Last visited October 30, 2012.

NHS choices (2012). Ten ways to boost your health. Available at http://www.nhs.uk/Livewell/healthy-living/Pages/Ten-ways-to-boost-your-health.aspx Last visited March 12, 2012.

Office for National Statistics. The National Statistics Socio-economic Classification (NS-SEC rebased on the SOC2010). Available at http://www.ons.gov.uk/ons/guide-method/classifications/currentstandard-classifications/soc2010/soc2010-volume-3-ns-sec--rebased-on-soc2010--usermanual/index.html Last visited March 12, 2012.

Samuel, G.N., Jordens, C.F.C., \& Kerridge, I. (2010). Direct-to-consumer personal genome testing: ethical and regulatory issues that arise from wanting to 'know' your DNA. Internal Medicine Journal, 40(3), 220-224.

Singleton, A., Erby, L.H., Foisie, K.V., \& Kaphingst, K.A. (2012). Informed choice in direct-to-consumer genetic testing (DTCGT) websites: a content analysis of benefits, risks, and limitations. Journal of Genetic Counselling, 21(3), 433-439. 
Smerecnik, C., Grispen, J.E., Quaak, M. (2012). Effectiveness of testing for genetic susceptibility to smoking-related diseases on smoking cessation outcomes: a systematic review and meta-analysis. Tobacco Control, 21(3), 347-354.

Spencer, D.H., Lockwood, C., Topol, E., et al. (2011). Direct-to-consumer genetic testing: reliable or risky? Clinical Chemistry, 57(12), 1641-1644.

UCL. Health and behaviour survey. Available at http://www.ucl.ac.uk/psychobiology/research/ihbsdetails/ihbsquestions Last visited March 12, 2012. 